\title{
Chlorotettix Van Duzee (Homoptera, Cicadellidae, Deltocephalinae): descrições de duas novas espécies ${ }^{1}$
}

\author{
Keti Maria Rocha Zanol ${ }^{2}$
}

\begin{abstract}
Chlorotettix Van Duzee (Homoptera, Cicadellidae, Deltocephalinae): descriptions of two new species. Two new species are described: Chlorotettix essbejus sp. n. (Peru) and Chlorotettix dentatus sp. n. (Colombia).

KEY WORDS. Homoptera, Cicadellidae, Deltocephalinae, Chlorotettix, Neotropical
\end{abstract}

O gênero Chlorotettix Van Duzee, 1892 caracteriza-se por apresentar a cabeça mais larga que o pronoto; coroa de comprimento uniforme, plana e densamente microesculturada; sutura coronal não ultrapassando a metade do comprimento da coroa; ocelos, na margem anterior, visíveis de cima; genas com reentrância abaixo dos olhos; anteclípeo de lados paralelos. Tégminas com duas células anteapicais fechadas. Espinulação das tíbias anteriores $1+4$ e dos fêmures posteriores $2+2+1$. Pigóforo geralmente com apêndices; tubo anal não esclerotinizado; placas subgenitais triangulares com macrocerdas unisseriadas; conetivo em forma de $\mathrm{Y}$; edeago simétrico com apêndices ou curtos processos; gonóporo apical ou subapical. Sétimo esternito da fêmea usualmente com fenda mediana. A coloração geralmente é amarela clara podendo ocorrer manchas escuras.

O material estudado está depositado nas seguintes Instituições: California Academy of Science, San Francisco (CASC) e Coleção de Entomologia Pe J.S. Moure, Curitiba, Paraná (DZUP).

\section{Chlorotettix essbejus sp. $\mathbf{n}$.}

Figs 1-6

Holótipo macho. Coloração geral amarelo-clara. Pigóforo sem apêndices e com uma coroa de espinhos esclerotinizados, próxima à margem ventro-apical. Placas subgenitais com as margens sinuosas. Estilos, em vista lateral, com apófises finamente serreadas e com uma projeção dentiforme, próxima ao ângulo pré-apical. Edeago com um par de apêndices apicais, divergentes, voltados para trás, quase tão longos quanto o edeago. Gonóporo subapical.

Fêmea. Externamente semelhante ao macho. Sétimo esternito com a margem posterior obliquamente escavada.

Comprimento total (em milímetros). Macho: 5,60; fêmea: 5,80.

1) Contribuição número 1215 do Departamento de Zoologia, Universidade Federal do Paraná.

2) Departamento de Zoologia, Universidade Federal do Paraná. Caixa Postal 19020, 81531-990 Curitiba, Paraná, Brasil. Bolsista do CNPq. 
Material examinado. Holótipo macho do PERU, Huánuco: Tingo Maria (Monson Valley), XII.29.1954, E.I.Schlinger \& E.S. Ross leg. (CASC). Parátipos. Ibidem: 1 fêmea (CASC); Ibidem, XI.29.1954, 1 macho, 1 fêmea (DZUP).

Esta espécie é próxima a C. spiniloba Linnavuori, 1968 que apresenta três fortes espinhos no ápice do pigóforo.

Etimologia. Do idioma Tupi: essbé = com e jú = espinho.
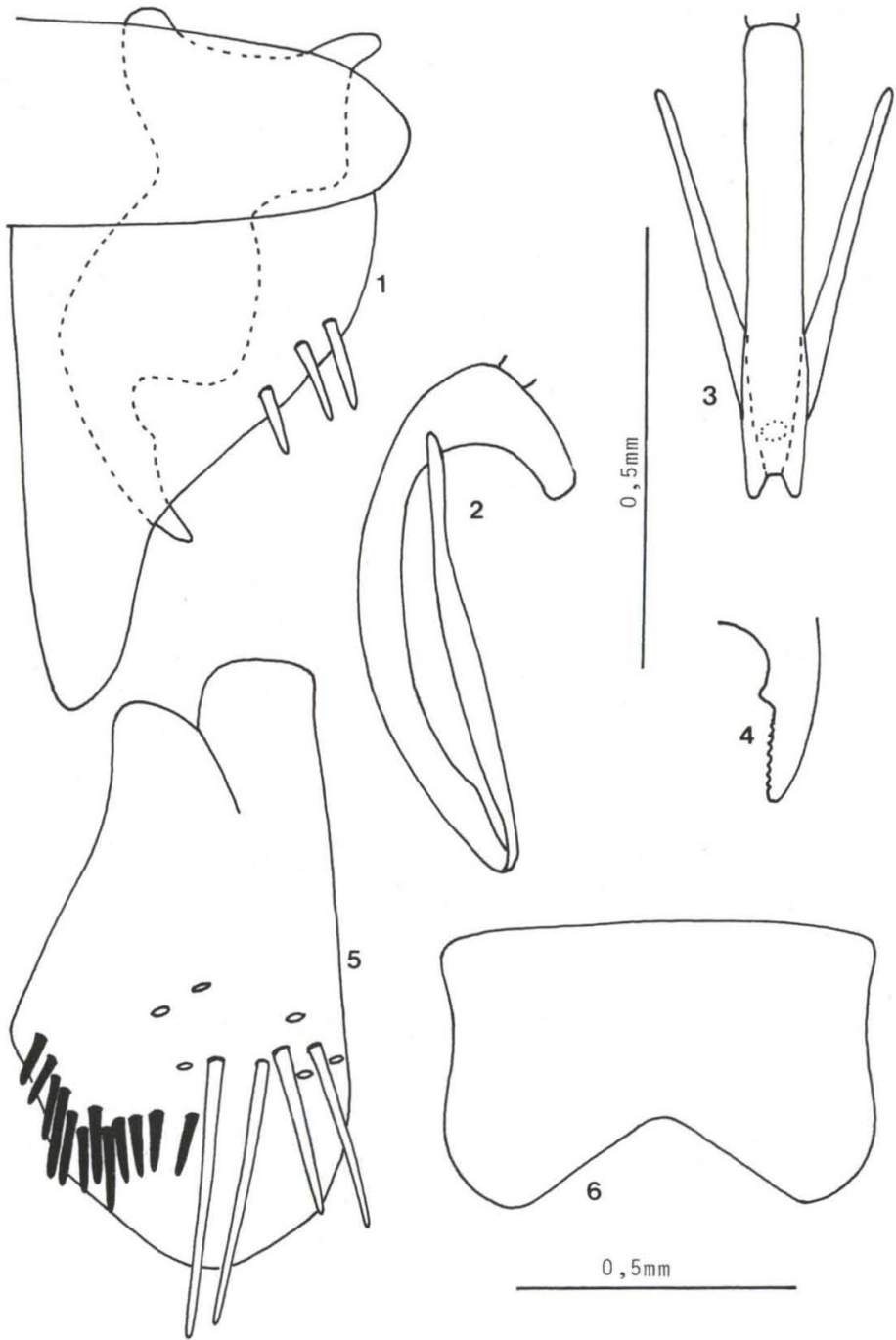

Figs 1-6. Chlorotettix essbejus sp. n., holótipo. (1) Valva genital, placa subgenital e estilo; (2) edeago, lateral; (3) edeago, ventral; (4) ápide do estilo; (5) pigóforo, lateral; (6) sétimo esternito da fêmea. 


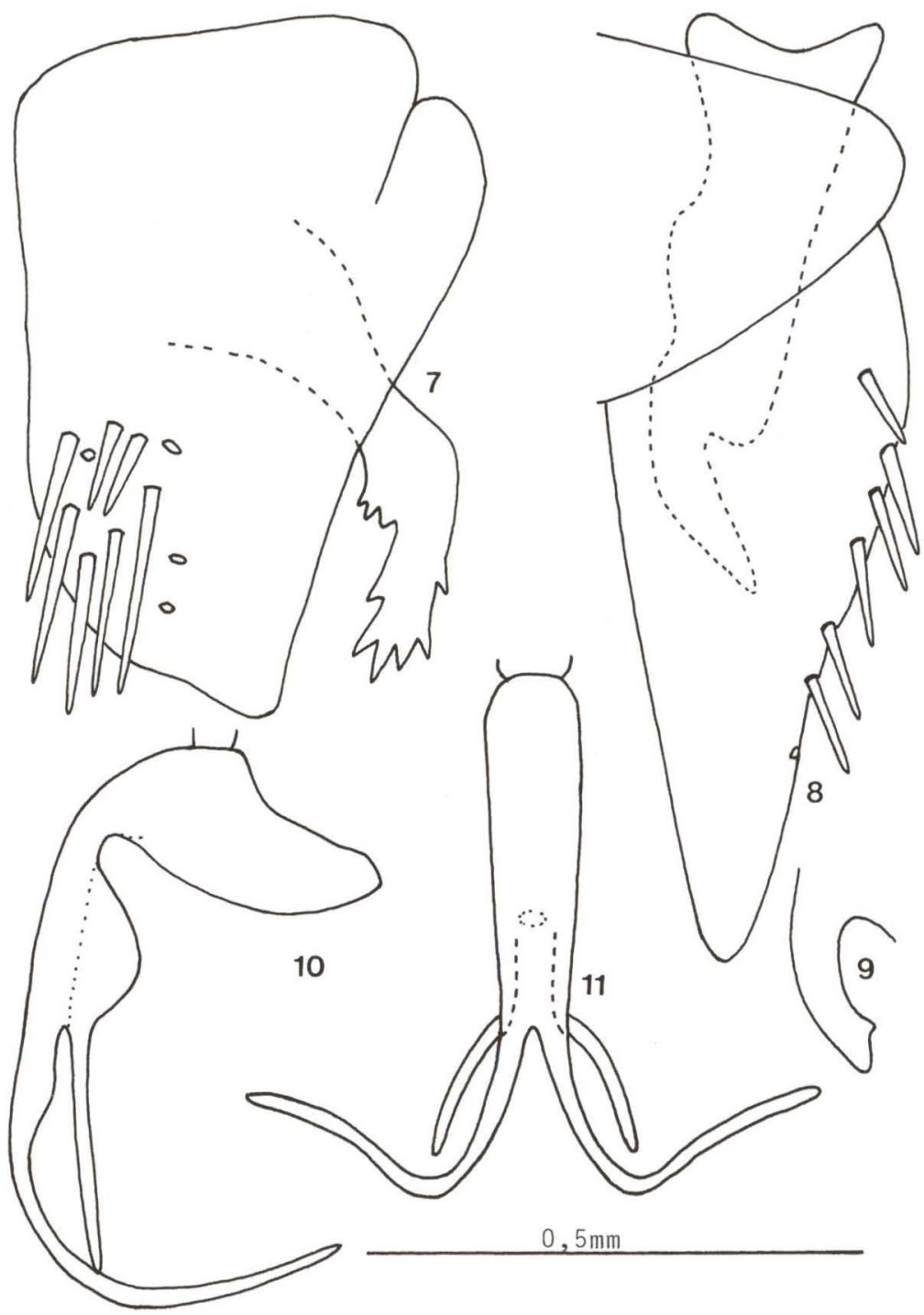

Figs 7-11. Chlorotettix dentatus sp. n., holótipo. (7) Pigóforo, lateral; (8) valva genital, placa subgenital e estilo; (9) ápice do estilo; (10) edeago, lateral; (11) edeago, ventral.

\section{Chlorotettix dentatus sp. $\mathbf{n}$.}

Figs 7-11

Holótipo macho. Coloração geral amarelo-clara. Pigóforo com um par de apêndices irregularmente denteado. Estilos, em vista lateral, com um processo dentiforme subapical. Edeago dorsalmente alargado, na metade apical, formando 
lobos deixando uma canaleta entre eles; com dois pares de apêndices; um par apical, maior, divergentes, curvo para cima e o outro par ventral, subapical, voltado para frente; gonóporo subapical.

Fêmea. Desconhecida.

Comprimento total (em milímetros). Macho: 5,30.

Material examinado. Holótipo macho da ColômBIA, Valle: $6 \mathrm{mi}$ w Calli, 1630 m, III.20.1955, E.I.Schlinger \& E.S. Ross leg. (CASC). Parátipos. Ibidem, 3 machos (CASC); S. Cartago, 960m, III.18.55, 1 macho (DZUP).

Esta espécie é próxima a C. minimus Baker, 1898 por apresentar os apêndices do pigóforo com as bordas externas serreadas.

Etimologia. O nome é devido a presença dos inúmeros dentes nos apêndices do pigóforo.

\section{REFERÊNCIA BIBLIOGRÁFICA}

LinNavuori, R. 1968. Contribución al conocimiento de la fauna Colombiana de cicadélidos.

Agricultura Tropical 24 (3): 147-156.

Recebido em 29.VI.2000; aceito em 07.V.2001. 